\title{
Teaching Modes for Manchu Language and Gulture
}

\author{
Zhao Aping *
}

\begin{abstract}
The paper is concerned with the combination of Manchu language teaching with culture teaching in two aspects, from which the basic teaching modes can be concluded. First, on the theoretical level, the author states the combined learning mode of ethnic language and culture learning in connection with the multi-cultural interactive mode, and analyzes its theoretic foundation. Second, on the practical level, the paper introduces some of the effective language and culture teaching methods, such as culture lectures, culture discussions, culture investigations, culture comparisons and culture research.
\end{abstract}

Key words: Manchu, language and culture, teaching, mode study

\section{Introduction}

The relationship between language and culture is complicated. They are two independent concepts, not exactly the same, but overlapping and closely related. Being part of culture, language mirrors culture and reflects the splendid cultural patterns of a nation. Featuring a distinctive national character, various cultures naturally have different connotations. Since the culture of every nation takes shape in a specific natural environment, historical conditions, geographic location and social reality, each of them is unique in the world. To master a language, we must study its underlying cultural specificity, and have an insight into its cultural connotations. By analyzing the relationship between language and culture, scholars have put forward a number of viewpoints from various angles, like Cassirer's theory of linguistic symbols, Heidegger's assertion on the relationship between language and being, Humboldt's view on the relationship of language and world views and national spirits, Boas, Sapir and Whorf's views of the relationship between language and culture, thought and world views, and Chinese linguist Luo Changpei's work Language and Culture, which systematically expounds the relationship between language and society. Social linguistics has developed in China for many years with a vast amount of relevant works and papers. I as well have published a series of essays exploring specific studies on the relationship between the Manchu language and Manchu history and culture. Manchu language and Manchu history and culture are naturally interrelated, and therefore we must

\footnotetext{
* Zhao Aping: Manchu Language and Culture Research Center, Heilongjiang University, Harbin, 150080, China. E-mail: zhaoaping19@126.com.
} 
combine the teaching and studying of both so as to achieve the purpose of resolving the real problem. This paper discusses the main teaching contents, teaching and research orientation and teaching modes to explore ways to combine Manchu language teaching with culture teaching purposefully, systematically and efficiently. It consists of two aspects, from which the basic teaching modes can be concluded. First, on the theoretical level, the author states the combined learning mode of ethnic language and culture learning in connection with the multi-cultural interactive mode, and analyzes its theoretical foundation. Second, on the practical level, the paper introduces some of the effective language and culture teaching methods, such as culture lectures, culture discussions, culture investigations, culture comparisons and culture research.

\section{Outline of Teaching Contents}

To combine the teaching of Manchu language and culture, we should first of all determine the corresponding systematic teaching contents and put them into effect logically, step by step. Meanwhile, we are supposed to teach the corresponding contents and help to improve learning skills according to the grounding and aptitude of different learners. Manchu language and culture cover a wide range of subjects. However, the teaching contents should be named in a corresponding scope, and the key points should be focused and supplemented with relevant contents. Furthermore, we ought to link basic theory with practice. The main teaching contents are listed as follows.

\subsection{Manchu Language}

(1) Its history and development

(2) Phonetics and written language studies

(3) Grammar

(4) Semantics

(5) Lexicology

(6) Literature review

(7) Oral speaking field work

(8) Translation theory and practice

(9) Language and literature

(10) Classical books study

\subsection{Manchu Language and Historical Culture}

(1) Characteristics of Manchu language and its relationship with culture

(2) Manchu language and natural environment

(3) Manchu language and economic culture

(4) Manchu language and social system

(5) Manchu language and religious belief 
(6) Manchu language and personal names and geographical names

(7) Manchu language and ethnic cultural exchanges

(8) Manchu idioms, proverbs, folk expressions and social culture

1.3 Special Subjects in Linguistics, History and Culture Studies

(1) History of Chinese ethnic relations

(2) Manchu and the Qing Dynasty history

(3) Introduction to linguistics

(4) Historical institutions of the Qing Dynasty

(5) Manchu studies

(6) Survey of ethnic language culture

(7) Introduction to cultural linguistics

(8) Introduction to Altaic linguistics

(9) Introduction to ethnology (anthropology)

(10) Comparative studies in linguistic culture

(11) Introduction to philology

(12) Introduction to Chinese-foreign cultural history

(13) Introduction to archival science

(14) Introduction to cultural philosophy

\section{Main Teaching and Research Orientation}

Manchu language and culture study, as an important discipline and academic focus, is marked by special national cultural features endowed with the advantage of international academic exchanges. At present, Manchu language has already been endangered, although a large number of precious historical archives have to be explored and utilized. As the international academic competition is becoming increasingly fierce in the 21 st century, it is essential to save the cultural heritage of Manchu language and also comprehensively study Manchu history and culture, even more urgently today, since it has great referential value and practical significance for the study of Chinese history and culture as a diversified whole, the rapid development of modern Chinese economy and culture and the adjustment of ethnic policy and foreign policy.

The objective of teaching Manchu language and culture is to cultivate highly qualified personnel with composite expertise based on the needs of scientific research, economic construction and social development. They are required to have certain research capability and practical competence, possess theoretical and analytical ability and be able to carry out scientific research and teaching on their own. They are supposed to read, translate and use Manchu documents and other related materials. They should be aware of the academic development and the latest achievements of the current international research of their home 
discipline. They ought to be able to identify authentic historical materials and be creative and innovative in research as well.

Research orientation of Manchu language and culture teaching includes studies on Manchu language and historical culture, studies on translation theory and practice of Manchu language and comparative studies in language and culture of Manchu and other relevant nationalities, which are listed as follows.

\subsection{Studies on Manchu Language and Historical Culture}

This orientation is mainly based on the theories of sociolinguistics, ethnic linguistics, and human cultural linguistics, exploring the relationship of Manchu language with its natural environment, economy, culture, social system, religious beliefs and ethnic culture. The focus is on the characteristics of Manchu language and its relationship with Manchu culture, so as to reveal the cultural connotations of Manchu vocabulary and explore Manchu language and cultural patterns.

Innovation in this regard not only lies in its theoretical and applied features, but also in its interdisciplinary and marginal features. It systematically delves into the characteristics of Manchu language and its relationship with history and culture from many aspects by combining linguistics with history, ethnology, cultural anthropology, archeology and other related disciplines, which breaks through the isolation of Manchu language from history and cultural study and paves a new way for Manchu studies. Meanwhile, attention is given both to theoretical studies and application, so that rescue excavation and the use of the precious heritage of Manchu language and culture play a special role in the social construction and development of human civilization. With distinct advantages and characteristics, Manchu language, history and culture studies open up a broad space for its development as a new growth point for academic research. We take the lead in Manchu studies internationally.

This study has broad prospects for application and development, since it has significant research and application value for a number of related studies, such as the laws of the origin, development and endangerment of the Manchu and Tungus language and culture, comparative studies on the Altaic languages, the relationship between the languages and cultures of the Han nationality and Northern China ethnic groups, studies of the Qing Dynasty, of cultural anthropology and history of the Manchu nationality. Through the in-depth and comprehensive studies of Manchu language, documents and historical culture, we explore the cultural patterns of Manchu language, which will provide reference both for the development of our economy and culture and the civilization of mankind.

\subsection{Studies on Translation Theory and Practice of Manchu Language}

Established as the "national language" and "Qing language" all over the country in the Qing Dynasty, Manchu language is used in numerous volumes of precious documents and 
historical materials, more than 2 million pieces in existence at present. Besides, a certain amount of them, concerning politics, history, economy, culture, military, diplomacy, religion, folklore, astronomy, and geography and so on, are in the possession of some museums and libraries in Russia, Japan, Germany, Britain, the United States, France and other countries. These documents promote social development, enrich the treasure house of Chinese culture, and count much for the studies of various disciplines in ancient and modern society, well deserving the title of "National Treasure" and "Invaluable Cultural Heritage of the World." Studies on Manchu language translation theory and application are of great historical value and practical significance, and therefore the investigation and salvage of existing heritage of the Manchu language and culture have become an urgent task.

Using historical linguistics, sociolinguistics, translation theories and approaches, and means of modern technology, a large number of precious ancient Manchu documents and materials can be translated and further studied, which provides original and reliable first-hand information for the studies of history, ethnic groups, borderland, geography, culture, religion and other disciplines, and promotes relevant researches in depth and breadth. At the same time, with the help of modern equipment and modern information processing technology, we can save and investigate the endangered spoken Manchu language by digitization of the data and establishment of Manchu language corpora. We can also establish a Manchu text database through a general survey of the existing Manchu documents throughout the world. This not only extends the field of Manchu language studies, promotes in depth researches, but also shortens the translation cycle of Manchu documents and enhances the efficiency of study and exploration, which means a lot to Manchu language, which is at the brink of extinction and short of qualified personnel. Studies on translation theory and practice of Manchu language extend a broad space for the development of Manchu culture studies and Manchu archival documents utilization, having important value and significance for Chinese history studies, construction and development of modern society and even for the research on the world civilization process.

2.3 Comparative Studies on Language and Culture of Manchu and Other Relevant Nationalities

By virtue of sociolinguistics and historical linguistic theories, this direction mainly explores the relationship of Manchu language and culture with other relevant nationalities, their intercourse and mutual influence, so as to reveal the communal relationship due to the long-term contact with each other and the plurality that results from historical development. The characteristics of this study lie not only in its interdisciplinary and marginal nature, but also in diversity and integrativeness.

The world consists of a number of nationalities, each contributing to the world 
civilization. In addition to their similarities in civilization, they do have differences. However, human civilization forges ahead just in the process of the exchanges and collision of all nationalities and that is what we want to reveal. From a unique perspective, it shows the cultural traits of each nationality and studies how they have influenced each other in the process of communication through comparative analysis of their language and cultural implications. In the long-term developing process, the Manchu nationality has made a significant contribution to the Chinese history and world civilization; it is especially in the establishment of the Qing Dynasty that we find the glorious history of its development. This comparative analysis with sociolinguistic theories from the perspective of nations and civilizations is not only significant for in-depth studies on the language and culture of the Manchu and other related nationalities, but it also plays a great role in promoting the multiple integration process of human civilization.

As an important nation among the Manchu-Tungusic language-speaking nationalities, the Manchu's language ranks one of the three major Altaic branches, and in the long historical development their mutual influence and connections have been very close. In addition, the problem of determining which branch its neighboring languages, Korean and Japanese, belong to has not yet been settled, however, the academia generally believe they belong to Altaic languages, and have an even closer relationship with the Manchu-Tungusic languages. This study will provide scientific proof and a reliable basis for the establishment of Altaic linguistic theory and help with the solution of the affiliation of the Korean and Japanese languages, which is a difficulty in international linguistics.

\section{Teaching Modes}

The focus of this paper lies in how to combine Manchu language teaching with culture teaching through a variety of methods, and how to enable learners to master the language and acquire the culture, which also plays a decisive role in the implementation of the Manchu language and culture teaching. This paper mainly puts forward two teaching modes - integrated ethnic culture learning mode and multicultural interactive synthesized mode, and discusses their theoretical foundation and teaching methods.

\subsection{Integrated ethnic culture learning mode}

Language is a social and cultural phenomenon, the foundation and essence of an ethnic culture. Early in the 1950s, insightful educators in America held seminars so as to expound cultural norms of language teaching. Renowned language educator W. Rivers pointed out: "Language spoken and written by native speakers can never be understood in isolation, but in the context of language and culture. Therefore, to teach a language means teaching the culture of the language speakers." (Rivers, 1964) In Language and Culture, based on a 
large amount of linguistic facts, Chinese linguist Luo Changpei shows the necessity and possibility of studying nationality and culture through language, and vice versa (Luo, 1989) . As the product of Manchu culture, Manchu language naturally differs from that of other nationalities in phonetics, grammar, semantics, vocabulary and other aspects. Therefore, we must analyze the cultural background under which Manchu language has taken shape and been used, and make an explanation of the cultural connotation it represents. For instance, for the differences and variations in pronunciation, semantic structure, word-formation, and cultural connotation of unique words, we need to analyze and explain various cultural factors behind them (Zhao, 1994). Manchu language courses should also take related historical and cultural contents into consideration so as to make the language and culture teaching complement each other and develop simultaneously.

\subsubsection{Lectures}

To teach the cultural contents added in the language courses, lecturing on culture is the most efficient and economical method. Teachers will give thematic introduction, explanation and analysis so as to prepare the students with a preliminary understanding of the targeted culture. The lectures are centered on the teachers, who lecture to students about the historical and cultural knowledge of Manchu language. For instance, the lectures on Manchu history, the studies of the Qing Dynasty, political institutions of the Qing Dynasty, the relationship of Manchu language with natural environment, economy and social system, religion, and the naming customs of people and places, Manchu language and ethnic cultural exchanges, Manchu idioms, proverbs, folk expressions and social culture, Manchu studies, survey of ethnic language culture, cultural linguistics, Altaic linguistics, comparative studies on linguistic culture, etc. should be given to enable students to learn the history and culture of the Manchu. The lectures in discussion can either be independent ones on a specific issue, or they can consist of a series of systematic lectures with certain aims. Each course can be composed of a lecture series.

The students should be informed of the expected learning effects of cultural lectures beforehand, so they can study, grasp the essentials and solve the unknown questions accordingly. Besides, timing is important. There must be a reasonable schedule of the courses. Though the keynote speakers of the lectures are the teachers, while the students only listen and take notes, a two-way interaction between them has to be conducted here. Ample time should be given for the students to bring forward their doubts and receive answers.

Cultural lectures reconstruct the fragments of cultural information, and, as an efficient teaching method, list all that is needed to illustrate a global notion. Eminent scholars are invited to deliver different topics. In this way, the teaching resources are used in the best possible way. Every lecture is fully prepared and pools the latest research findings with the 
most advanced methods.

\subsubsection{Discussions}

Cultural discussions and lectures do have some similarities. The differences between them lie in the following: in discussions, the teacher plays the role of an organizer who encourages students to carry out a progressive and face-to-face discussion, which is supposed to solve a practical problem in a specific field, and at the same time guides the students to deepen their understanding of a particular issue. The students partly benefit from teachers' appropriate instruction, but the most important part is the students' participation in the discussion itself. It is critical that the students are prepared beforehand or actively involved in the discussion. The cultural discussion is a typical two-way interaction between teachers and students.

Various ways can be used to organize cultural discussions, but they all have some features in common. Discussions of high quality are purposeful, communicative, insightful and mutually helpful with minimal dispute, persuasion and moralizing. The students are not concerned about the correctness of suggestions, nor do they come to obey others or impose their views. Instead, what they aim at is a profounder understanding of the issue in question. The teacher, as the organizer and host, should not consume too much time, but make the students do the talking. And when he speaks, it is to hint or correct, rather than to do a Q\&A. Thus, it is the natural interaction that the teachers should seek instead of posing questions.

Cultural discussions should be open and free. They are not pre-determined or answer-directed. Therefore, the teacher should first give a Manchu related topic, for instance, A Comparative Study of Manchu and Other Nations' Languages and Cultures. To stimulate the thinking of students and make the discussion topic-centered, an outline could be drawn by the teacher to guide the students in several aspects. Discussions can be used together with other teaching methods such as lectures, investigations and/or comparative studies. A discussion held after a lecture or expedition is appropriate, and will support the students to digest and consolidate their learning while developing the skill of independent thinking and analyzing, synthesizing, etc.

\subsubsection{Investigations}

Cultural investigations are conducted by the students with the help of teachers. Targeting at a certain cultural study, it is a teaching method that relies on field trips to make the students observe and perceive directly, and then finally achieve the expected learning effects. Cultural investigations cover a wide range of activities, including visits to Manchu language teaching related museums, exhibitions, archives and ethnic areas. This is a major way to combine theory with practice. The rudiments and overall impression mentioned by teachers in lectures can be verified and strengthened in expeditions; meanwhile, the 
cultural evidence and data collected can also be used to expatiate and support new ideas.

The teacher's organization and preparation bear direct impact on the results. Before the expeditions, a teacher should require students to list an observation outline with defined tasks, according to which they can explore with full initiative. After that, a report will testify the achievements of the students. The impression they get through this is more direct, and the students' understanding will move to a profounder level. Besides, knowledge is not the only harvest: the students' capacity of independent work is also increased. The cultural investigations of Manchu language can be launched in a Manchu language residue zone or other language zones which belong to the same language family: an investigation about Manchu language in San Jiazi Village and Heihe area of Heilongjiang Province; an investigation of Xibe language in Chabuchar County in Xinjiang Autonomous Region; an investigation of Hezhe language along Tongjiang River and Heilongjiang River; an investigation of Oroqen and Ewenki languages in field work; and an expedition in the Manchu and Tungusic language-speaking zone in Russia. Thus the cultural background of language formation and application can be comprehended, and by comparison and contrast the students will grasp the changing cultural elements in history and reality.

\subsection{Multicultural interactive synthesized model}

At least two cultures must be referred to in ethnic language teaching practice: the home culture (the culture of your own nationality) and the object culture (the language culture to be learned). It is quite common that people from different backgrounds hold different views towards the same thing in this multicultural society. In the learning process, the learner continuously explains the unknown culture of other nations with the known culture of his own, compares and analyzes them when differences and conflicts occur. This multicultural interaction imbeds a "cultural pluralism" in students. This inner change of learners embodies another merit of this kind of teaching, from which we know the study of language and culture is not only progressive, but also an unconsciously influential progress for the learners. With accumulating knowledge and expanding horizons, students will become more quick-witted and more perceptive to the new culture. Incorporating both cultures in Manchu language teaching and conducting two-way cultural comparison will have greater benefits. Moreover, teachers and students with multicultural backgrounds will also interact with each other and make comparisons which they can explore together.

\subsubsection{Comparison}

People's lifestyle varies due to regional and temporal differences and hence cultures are diversified. However, there are obviously some similarities in spite of all kinds of discrepancies. The method of culture comparison deals with the substantial, social, linguistic and spiritual similarities and differences among different nationalities and races by means of anthropology, history, linguistics, ethnology, cultural studies, archeology, 
folklore, sociology, religious studies and other disciplines, to explore their exchanges and mutual influence while studying their relations and development. The Manchu have a long history with complex changes. In the process of development, the people of Manchu and their ancestors intermingled with other nationalities, assimilating their cultures, in particular, with the Mongolians and the Han nationality. In this way, they influenced and promoted each other. Through the comparison of languages and cultures, between the Manchu and other relevant nationalities, learners can comprehend their similarities and differences and further explore their communication, mutual influence, penetration and assimilation. To name a few, the comparison of languages and cultures can be made between the Manchu and other nationalities of the same language family, such as Hezhe, Xibe, Oroqen and Ewenki, between the Manchu and the Han and also between the Manchu and the Mongolians.

Cultural comparison can be conducted by way of lectures, discussions, investigation and research. Based on the existing knowledge about their own culture, teachers and students can make a comparison to identify the similarities and differences and probe into their background and connotations on a deeper level. By multicultural comparison and interaction, the students' insights will be developed and the teaching effect reinforced.

\subsubsection{Research}

The research of culture is a complicated matter which represents a further development of teaching. The teaching process of cultural research takes the form of systematic study of researching and investigation with clear aims. In learning, the students have to explore and discover new things on the basis of what they know. As instructors, the teachers help and guide the students in terms of orientation, scope, methodology and materials of the research. On the other hand, the students should collect cultural information and data, launch expeditions and further study the particular cultural topics. For instance, if we study the relationship between Manchu names and culture, several questions will be proposed: a. the construction of Manchu names and their historical changes; $b$. the origin and implied meaning of surnames; $c$. the choice of given names and their constitutive features. A large amount of data needs to be collected and analyzed by students to study the characteristics and relations of Manchu names and culture from the perspective of thinking patterns, national psychology, eco-environment and social surroundings.

Based on cultural lectures, discussions, investigations and comparison, cultural research makes a demanding teaching and learning method at high level. It is not only multicultural interaction, but interaction between teachers and students as well. Students are encouraged to deeply comprehend the relationship between language and culture. The knowledge that students gain and the training they get from it are extremely comprehensive and extensive. Besides, this process demonstrates to the students the significance of their prior knowledge, 
without which the new is not attainable. Cultural research can help the students enhance their ability of independent thinking, problem solving, exploration and innovation.

\section{Conclusion}

In this paper, we explore and summarize the basic mode of Manchu language teaching by discussing in details its content, research orientation and methodology, on both theoretical and practical level. We can see on one hand, or theoretically, the foundation for Manchu language and culture teaching is the combination of the learning acquisition mode and the multicultural interactive mode. On the other hand, practically, Manchu language teaching makes use of all kinds of effective teaching methods, such as Manchu language related cultural lectures, investigation, comparison and researches. This teaching process comprehensively embodies the combination of language and culture, theory and practice and also its cross-disciplinary nature, encourages interactions between teachers and students, and also exercises students' initiatives to improve their learning and ability of independent thinking, problem solving, exploration and innovation.

\section{References}

Luo Changpei. 1989. Language and Culture[M]. Beijing:Language Press.

Rivers, W.M. 1964. The Psychologist and the Foreign Language Teacher. Chicago: University of Chicago Press.

Zhao Aping. 1994. Cultural factors in Manchu Language Teaching and Research[J]. Journal of Minzu University of China.

(Translated by Pan Yue and Zhang Yan) 